\title{
Rare Abdominal Wall Malformation: Case Report of Umbilical Cord Hernia
}

\author{
Andro Gliha' ${ }^{1, *}$, Andrija Car ${ }^{1}$ Stjepan Višnjićc ${ }^{1}$, Bozidar Zupancic ${ }^{1}$, Karmen Kondza², Ivan Petracic ${ }^{1}$
}

\section{ABSTRACT}

The umbilical cord hernia is the rarest form of abdominal wall malformations, anatomically completely different from gastroschisis and omphalocele. It occurs due to the permanent physiological evisceration of abdominal organs into umbilical celom and persistence of a patent umbilical ring. The umbilical cord hernia is often mistaken for omphalocele and called "small omphalocele". Here we present a case of a female newborn with umbilical cord hernia treated in our Hospital. After preoperative examinations surgery was done on the second day of life. The abdominal wall was closed without tension. The aim of this article is to present the importance of the proper diagnose of these three entities and to stimulate academic community for the answer, is this umbilical cord hernia or small omphalocele.

\section{KEYWORDS}

umbilical cord hernia; omphalocele; gastroschisis; abdominal wall malformation

AUTHOR AFFILIATIONS

${ }^{1}$ Department of pediatric surgery, Children's Hospital Zagreb, Croatia

${ }^{2}$ Department of anesthesiology, reanimatology and intensive care, Children's Hospital Zagreb, Croatia

* Corresponding author: Children's Hospital Zagreb, Klaićeva 16, 10000 Zagreb, Croatia; e-mail: agliha@gmail.com

Received: 7 March 2017

Accepted: 6 August 2017

Published online: 5 February 2018

Acta Medica (Hradec Králové) 2017; 60(3): 127-130

https://doi.org/10.14712/18059694.2018.6

(C) 2017 The Authors. This is an open-access article distributed under the terms of the Creative Commons Attribution License (http://creativecommons.org/licenses/by/4.0), which permits unrestricted use, distribution, and reproduction in any medium, provided the original author and source are credited. 


\section{INTRODUCTION}

The umbilical cord hernia, gastroschisis, and omphalocele comprise the group of congenital malformations of the ventral abdominal wall. The umbilical cord hernia is the rarest form of these malformations, anatomically different from gastroschisis and omphalocele. It occurs due to the permanent physiological evisceration of abdominal organs into umbilical celom and persistence of a patent umbilical ring (Figure 1). Gastroschisis occurs due to the evisceration of abdominal organs through the defect of the abdominal wall on the side of the obliterated right umbilical vein, always to the right of the umbilical cord (Figure 2). Omphalocele occurs because of an anomaly in the lateral folding of the embryonic disc during the formation of the abdominal wall (1) (Figure 3). The Umbilical cord hernia is often mistaken for omphalocele, but unlike omphalocele, the hernia is a smaller defect with a normal, physiological insertion of the umbilical cord and formed muscles of the abdominal wall. Omphalocele is a more serious defect of the abdominal wall, with eviscerated abdominal organs covered with amniotic membrane, with the more lateral insertion of the muscles of the abdominal wall to the thorax. Newborns with omphalocele have the worst prognosis due to the high rate of related congenital and chromosomal anomalies. The biggest macroscopic difference between omphalocele and umbilical cord hernia is the recognizable umbilical cord insertion, which, in the case of omphalocele, is at any part of the amniotic membrane, as compared to the dermal fold around the umbilical ring in umbilical cord hernia (2).

It is important to properly diagnose the three entities to ensure proper treatment and prognosis.

\section{CASE REPORT}

A female newborn was born in the 39th week of gestation by an emergency $\mathrm{C}$-section due to fetal hypoxia and bradycardia, and it was referred to our hospital with a diagnosis of omphalocele. Apgar was 7/9, birth weight 3010 grams, length 50 centimeters, and head circumference 36 centimeters. The omphalocele was suspected during the 11th week of gestation on the ultrasound examination, with a later seen cyst of the umbilical cord. Prenatally, there was a suspected type II agenesis of the ductus venosus. Due to common congenital anomalies and chromosomal aberrations in children with ompalocele, a chorionic villus sampling in the 12th week of gestation showed a normal female karyotype. The omphalocele and cyst of the umbilical cord were monitored until birth.

A check-up of the newborn established a diagnosis of umbilical cord hernia instead of omphalocele. The clinical status was dominated by a centrally positioned smaller abdominal wall defect, 3 centimeters in diameter. The hernia sac was located above the defect and it contained vital loops of the small and large intestine. Above the hernia sac, extending from the umbilical cord, there was a cyst filled with clear yellowish fluid. The insertion of the umbilical cord and its blood vessels was physiological, but there were only one vein and one artery present. We found dermal fold around the umbilical ring, typical for umbilical cord hernia. Otherwise, there was a slight head dysmorphia (dominant neurocranium, prominent frontal eminence, lower set of auricular and saddle nose) and a skin covered intergluteal groove in the sacral region of the vertebrae.

The following day, surgery was performed under general anesthesia. The hernia sac was accessed through the lower edge of the cranial side of the hernia sac. During exploration, loops of the small and large intestine were found adherent in a few places to the inner wall of the hernia sac. We didn't find associated anomalies of the intestines. After adhesiolysis, the contents of the hernia sac were returned to the abdomen without resistance, followed with complete excision of the hernia sac. The abdominal wall was closed without tension. The navel was reconstructed using Steri-strip (Figure 1).

Early post-operative course was uneventful. Peristalsis was present from the second post-op day, and peroral feeding started on the third post-op day.

A comprehensive check-up was conducted: cardiologist, neuro-pediatrician, EEG poligraphy, neurosurgeon, radiological check-up, orthopedist, physiatrist, ENT, geneticist. There was generalized hypotonia, dysmorphia with less severe dysplastic features. Ultrasound examination of the heart showed an open ductus arteriosus, foramen ovale and mild mitral insufficiency.

The child was released to home care on the eighteenth post-op day with regular weight gain, appetite and bowel movements. She is regulary followed up. Ultrasound examination of the heart still showes open foramen ovale, without previously mentioned open ductus arteriosus and mild mitral insufficiency. Despite the last normal physical and neurological finding, she is still under neuropediatrician and physiatrist care due to earlier deviation in her development and hypotonia. MRI of the brain was preformed due to ultrasound finding of the hypoplasia of the corpus callosum, which showed normal brain development. EEG showed normal brain activity. Genetic tests were normal, with chromosomal microarray analysis still in progress.

\section{DISCUSSION}

Umbilical cord hernia is the rarest form of ventral abdominal wall anomalies that is embryologically and anatomically different from gastroschisis and omphalocele. Unlike omphalocele which appears in the earliest stages of embryonic development - during the folding of the lateral folds and the forming of the peritoneal cavity - the umbilical cord hernia appears later when the peritoneal cavity has already been formed (1). Physiological evisceration and rotation of the intestine into the umbilical celom takes place from the 5th to the 12th week of gestation. Umbilical cord hernia appears into the 10th to 12th week of gestation, when the return of intestinal loops from the umbilical celom into the peritoneal cavity is terminated (1). Umbilical cord hernia is characterized by a milder defect to the abdominal wall, $2-3 \mathrm{~cm}$ in diameter, centrally positioned next to the physiological insertion of the umbilical cord, as shown in Figure 1. Hernial sac contains the loops 


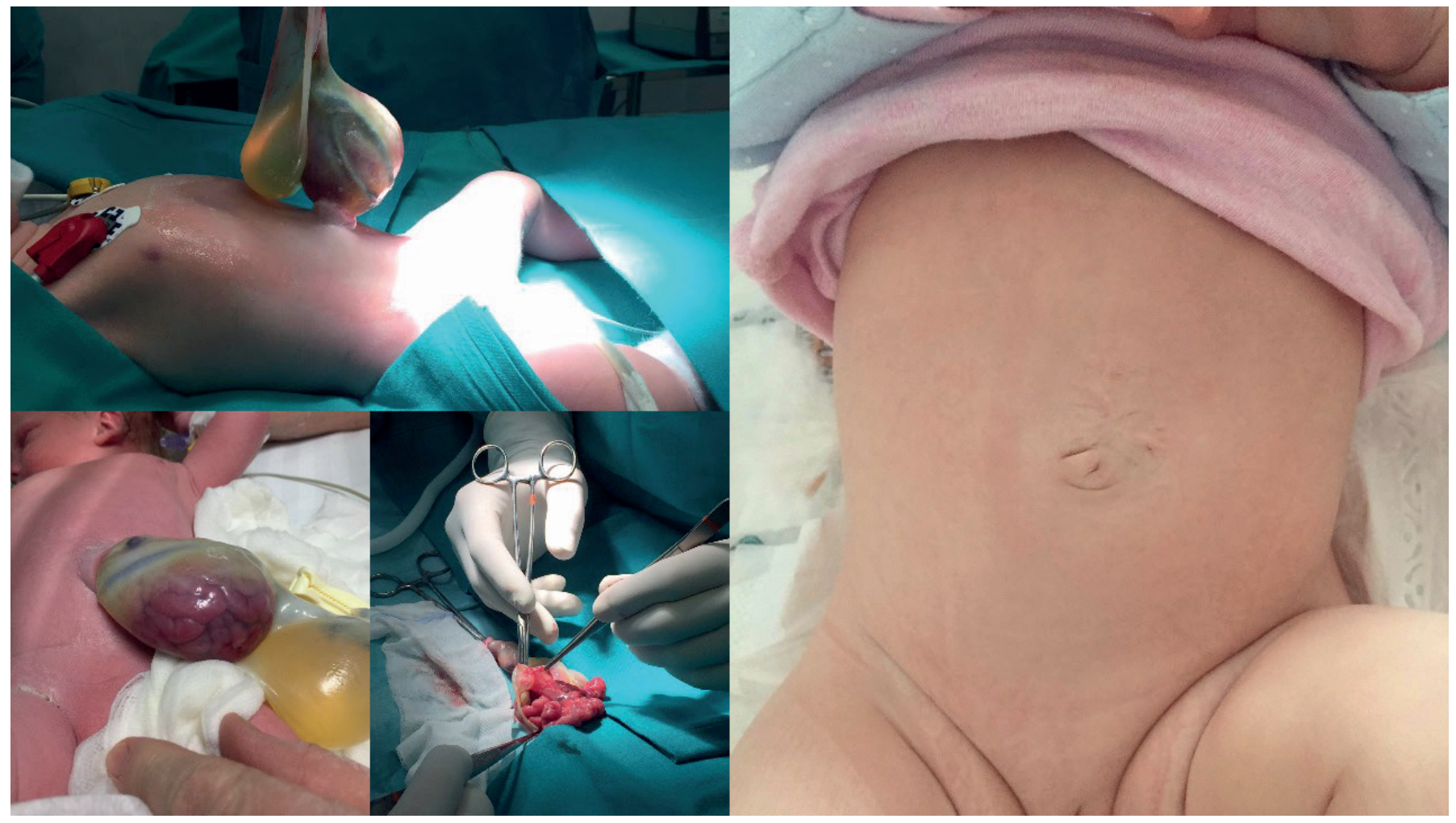

Fig. 1: Umbilical cord hernia.

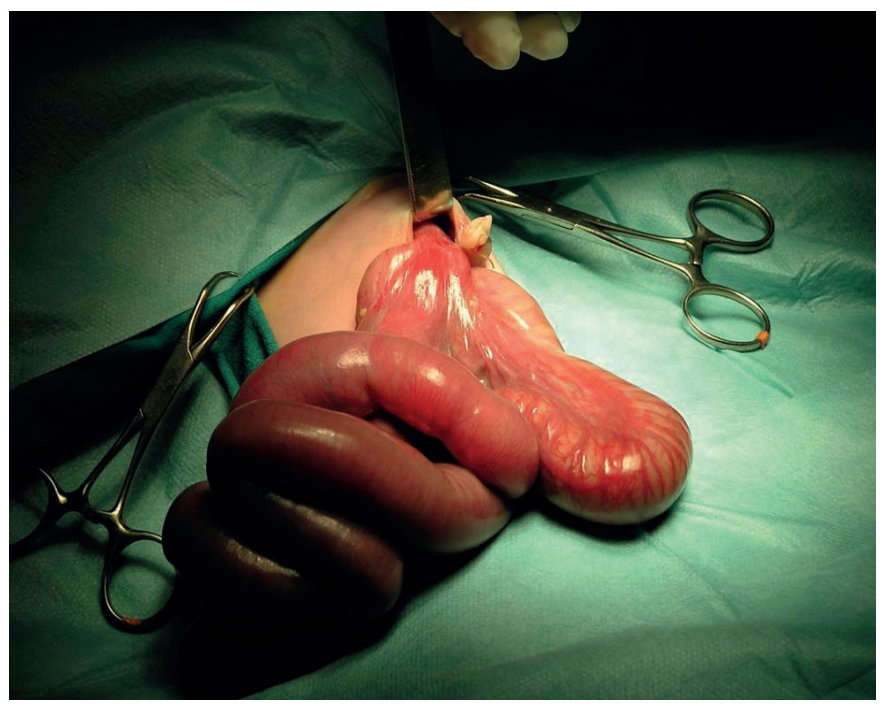

Fig. 2: Gastroschisis.

of both the small and the large intestine and rarely the liver and the gallbladder. Associated anomalies and chromosomal aberrations happen rarely, as shown by Haas et al, who described a series of 7 newborns with umbilical cord hernia whose amniocentesis had normal karyotype, as in our case $(2,3)$.

The navel was reconstructed by turning the skin in the anatomic region of the umbilicus using forceps and fixing it with Steri-Strip without using stitches. That resulted in a more cosmetically pleasing look of the umbilicus when compared to the reconstruction using purse string stitching.

Umbilical cord hernia belongs to the same group of defects that also includes omphalocele, and is often misdiagnosed as a small omphalocele $(4,5)$. The aim of treatment

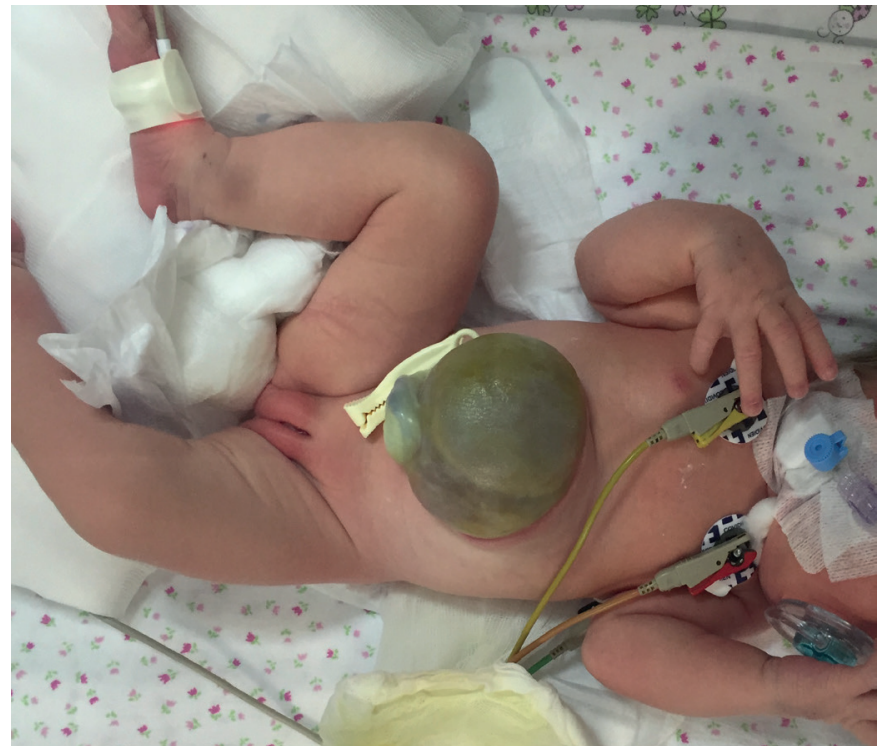

Fig. 3: Omphalocele.

is the same, reconstructing the ventral abdominal wall while repositioning the abdominal organs into the abdomen. However, the prognosis is different due to the higher occurrence of associated congenital and chromosomal anomalies in children born with omphalocele. Moreover, there is a well-documented risk of iatrogenic injury to the intestinal loops in the hernia sac while clamping the umbilical cord (6).

In conclusion, there is a clear difference in the onset and outcome of umbilical cord hernia when compared to omphalocele which is often accompanied by congenital anomalies and chromosomal aberrations. The prenatal diagnosis of omphalocele may cause the parents to feel uneasy and anxious, as well as make them decide on ar- 
tificial abortion (3). Such a destiny would be a tragedy for any family, because the termination of a pregnancy with maximal chance for healthy life of the child would be performed. A much higher awareness about this entity is needed among the caregivers to prevent from deleterious effects of false decision making.

\section{REFERENCES}

1. Grosfeld JL, O'Neill JA Jr, Fonkalsrud EW, Coran AG (2006). Congenital Defects of the Abdominal Wall. In: Pediatric Surgery, 6th edn. Mosby/ Elsevier, pp. 1157-1170.
2. Haas J, Achiron R, Barzilay E, Yinon Y, Bilik R, Gilboa Y. Umbilical Cord Hernias: Prenatal Diagnosis and Natural History. J Ultrasound Med 2011; 30: 1629-1632.

3. Raju R, Satti M, Lee Q, Vettraino I. Congenital hernia of cord: an often misdiagnosed entity. BMJ Case Rep 2015; pii: bcr2015209642.

4. Pal K, Ashri H, Al Wabari A. Congenital hernia of the cord. Indian J Pediatr 2009; 76(3): 319-21.

5. İnce, E, Temiz, A, Ezer SS, et al. Poorly understood and often miscategorized congenital umbilical cord hernia: an alternative repair method. Hernia 2017; 21(3): 449-454.

6. Cizmeci MN, Kanburoglu MK, Akelma AZ, Tatli MM. Do not overlook an umbilical cord hernia before clamping. Eur J Pediatr 2013; 172(8): 1139. 